\title{
The role of cognitive science in the promotion of humanitarian knowledge in higher education
}

\author{
Larisa Abrosimova ${ }^{1}$, Marina Bogdanova ${ }^{2 *}$ \\ ${ }^{1}$ Southern Federal University, Institute of Philology, Journalism and Intercultural \\ Communication, 344006 Rostov-on-Don, Russia \\ ${ }^{2}$ Southern Federal University, Institute of Philosophy and Social-Political Sciences, 344006 \\ Rostov-on-Don, Russia
}

\begin{abstract}
The article discusses the main milestones in the development of cognitive science, which from the very beginning has been a synthesis of natural and humanitarian knowledge. The authors not only emphasize the need to strengthen the role of humanities (philosophy, linguistics, psychology, cultural studies, etc.), without which serious research projects in the field of cognitive science are literally impossible, but also point out the importance of cognitive science in the promotion of humanities in universities. Turning to the work of the representatives of Russian cultural and historical psychology L.S. Vygotsky and A.R. Luria, the authors try to show that their idea that culture is a system of supra-individual regulators that permeate mental and material-objective life forms preceded some basic settings of the cognitive paradigm long before its official establishment.
\end{abstract}

The realities of modern university education in Russia are such that humanitarian education feels superfluous and uncomfortable. Such disciplines as cultural studies, linguistics, philology, logic disappear from university curriculum even at humanitarian departments, the courses of philosophy and psychology, history and art studies are reduced as abstract disciplines not corresponding to world scientific trends, disciplines that do not give concrete applied knowledge and secure income.

Leading managers and the recently introduced system of effective management in Russian universities are designed to optimize costs, and effective contracts imply carrying out of "revenue-generating activities." Naturally, specialists in humanities can not rival with experts in technical and natural sciences in terms of the financial profitability of their projects, publication activity in highly cited journals and the number of approved grants for their research. In universities humanities spoil indicators in this regard, they become unnecessary for the target of modern education: "training for the modernization of the Russian economy", and, as a result, university managers reduce humanitarian disciplines, abolish humanitarian departments, reduce study hours, transfer humanitarian disciplines from the category of mandatory to the category of optional disciplines. Moreover, the role of the modern teacher in these conditions is also changing - they are expected to show high Hirsch index, to have Scopus publications, to make efforts to attract students to commercial courses

\footnotetext{
* Corresponding author: maraleks27@mail.ru
} 
and departments, playing the role of a tutor who directs, regulates, rather than teaches. Today no one speaks about the educational role of the teacher, the teacher who in traditional Russian culture is not just a bearer and translator of information, but a person, authority, enlightener, inspiring students and promoting humanitarian culture.

Over the past thirty years, the place and structure of humanitarian knowledge in the world practice has radically changed, but not towards its exclusion and reduction; today interdisciplinary areas are highlighted and the humanitarian component of interdisciplinarity is widely recognized and represented impressively. The range of humanitarian knowledge application spheres is very extensive, however, the scientific areas lying at the junction of natural and humanitarian knowledge are especially relevant today.

In this article the authors try to show the fallacy and shortsightedness of the approach which expels humanitarian knowledge from university education and which can sideline and exclude Russian science from the most advanced research programs based on cognitive science.

High-technology computer era gave rise to the scientific research aimed at the creation of "artificial intelligence". This task caused the formation of a new science - cogitology (cognitive science) (from Latin kogitare - to think), which aims to integrate the achievements of different disciplines, thus representing an interdisciplinary field of research.

Cognitive science is based on the achievements of neuroscience, psychology, linguistics, anthropology, cultural studies, etc. All these disciplines are integrated around a common, central problem - the problem of human cognition, understood as a combination of the processes of acquisition, storage, transformation, use, transfer of knowledge by living and artificial systems.

Merely listing of the sciences that make up cogitology already suggests that it is too early to give up on humanitarian studies, but, on the contrary, this component should be strengthened and promoted in university education programs. The authors of the article "The aspects of application of the cognitive approach in humanitarian sphere" state that cognitive science is a qualitative, but not a quantitative science [1].

As it is known, the birth of cognitive science was caused by many interconnected processes: historical, political, economic and scientific.

Scientific prerequisites of cognitive science formation include the advances in understanding of cognitive processes nature: the creation of a computational model of the mind in mathematical research (A. Turing, K. Shannon); the development of the models of the mind based on the principles of processing cognitive information in neural networks (W. McCulloch, W. Pitts, K. Lashley); the advances in cybernetics, which developed the theory of information and a computer model for understanding computer systems (N. Wiener); the development of discursive psychology and narratology (J. Bruner, J. Brockmeier, R. Harre) and others [see 2].

Despite the fact that the generally accepted starting point of the cognitive science is considered to be the symposium at Massachusetts Institute of Technology in 1956 where several reports were devoted to the issues of consciousness modeling, the founders of the cognitive science themselves believed the French researcher J. Piaget and Russian scientists L.S. Vygotsky and R.A. Luria to be the forerunners of cogitology and noted the interdisciplinary nature of the new science.

The development of cognitive science has gone through several stages. The cognitive science of the "first generation" (the so-called symbolic stage of its development) was under the influence of analytical philosophy and was guided by the Cartesian idea of psychophysiological dualism. "Reason in the framework of this theory was considered "incorporeal and literal", existing autonomously and indifferently to human corporeality, and was described in functional terms» [3]. G. Lakoff, one of the founders of cognitive linguistics, noted that within the framework of the objectivist approach "The mind is an abstract machine, 
manipulating symbols essentially in the way a computer does, that is, by algorithmic computation" [4].

Thus, the cognitive science of the first generation drew upon the "computational" potential of the mind, which allowed scientists to consider reason as analogous to a computer, and, consequently, early cognitivists modelled thinking following theoretical logicalconceptual cognitive schemes and ignoring everyday practical knowledge gaining.

The foundations for the development of the computational model of the mind, as it is mentioned above, were laid by mathematicians A. Turing, C. Shannon, neurophysiologists W. McCulloch, W. Pitts, K. Lashley.

The second stage in the development of cognitive sciences began in the 1970s with the work of cognitive psychologists (J. Bruner, U. Neisser) and cognitive linguists (G. Lakoff, M. Johnson, D. Beaver, J. Carroll, etc.) The core of the "second cognitive revolution" was the return of the science to man after the "long cold winter of objectivism" [5].

G. Lakoff insists on the importance of a person's body organization in the formation of thinking. Human thought is determined by the nature of the organism, which ensures its (thought) functioning, and by all those factors that contribute to the accumulation, comprehension and relevant application of experience - this is genetic inheritance, person's environment, and the way people exist in it. In fact, G. Lakoff became the author of a new concept - the corporeality of the mind, which is quite radical for classical philosophy, thereby creating an interdisciplinary space for productive interaction between representatives of humanitarian and natural knowledge.

The cognitive science of this stage was increasingly asserting the thesis that "thinking has a bodily basis, it is more than just operating with abstract symbols" [6] and language is "an interface between consciousness and the brain, consciousness and the world" [7].

Thus, the main vector in the development of cognitive science of the second generation can be considered as its return from the abstract "information processing system" back to man as a being endowed with a physical body, an emotional-volitional sphere, incorporated into society and interacting with people by means of language [8].

It should be noted that similar intuitions that are easily read in the works by Russian scientists were expressed earlier than the cognitive paradigm took its complete form and acquired all the signs of institutionalism. This is, for example, the idea of organoprojection, which was developed by P. Florensky [9]. This theory confirms the experimental nature of cognition, based on the "tool-active" theory of anthropogenesis. The basis of this theory is the postulate that cultural activity is a constant unconscious process of a person's "selfdiscovery" in the outside world. "Organoprojection manifests itself in the fact that a person turns his body and its organs into scales and standards for nature, according to which not only measurement is made, but also assessment of its (nature) various phenomena and processes" [10].

In modern science, Russian researchers continue to develop the thesis of the importance and even the historically-classifying role of the man's bodily nature in world acquisition. V. Vs. Ivanov, a Russian linguist and language historian, writes about the differences in the stages of culture development depending on the use and attitude to the person's bodily organization, he says that the main "line between the early stages of culture and the culture we live in is that in our culture the main thing is not done with the help of the human body, but with the help of special devices taken out " [11]. Naturally, the abundance of technical devices these days is changing not only the structure and functions of the parts of our body, but also their role in the surrounding world acquisition.

The third stage of the cognitive science development in the 1990s of the XX century is called neural network or connectionist period and the main focus now is placed on culture; the determination of consciousness and cognition is associated with the regulatory role of 
culture in human consciousness and cognition (D. Dennett [12], W. Goodenough [13], R. D'Andrade [14], M. Cowell [15], C. Geertz [16]).

The cognitive system is considered as an isosceles triangle, the vertices of which are the brain, body and external environment (culture). D. Dennett describes consciousness as a complex phenomenon that forms at the junctions, "created by the overflows of the natural and cultural" [17].

Here, it is appropriate to mention that the "cognitive theory of culture" was actively developed in the USSR within the framework of cultural-historical psychology (L. S. Vygotsky, A. R. Luria) several decades before the cognitive science was born.

The core of L.S. Vygotsky, A.R. Luria's concept is the following idea: cognitive units and operations are primarily determined more by the state of culture inherent in the society than genetically or by learning in ontogenesis [18].

Culture in Vygotsky and Luria's concept represents a three-tiered formation.

It is known that basically human activity is under the control of consciousness. The effectiveness of consciousness is provided by instrumentation, which is culture. Man is a social being and therefore needs supra-individual regulations of his activity. Supraindividual regulators, worldview senses, value orientations make up the upper tier of culture and direct collective behavior. However, collective senses governing the behavior of a person can work in the mind only if realized in plans, cognitions, concepts, cognitive forms. Cognitive forms of consciousness represent the middle tier of culture, however, consciousness does not exist for the sake of consciousness. Man strives to make the world liveable. And for this, substantive activity is necessary, which is embodied in various artifacts: tools, instruments, material constructions. They help to make the world more people-friendly, more suitable for life, and therefore the system of artifacts represents the most developed, lower tier of the culture. These three mutually complementary tiers of culture evolve together on the principles of self-organization. Due to the above-mentioned reasons, cultural science is a necessary structural unit of cognitive science.

L.S. Vygotsky never considered human mind as an embodiment of logic calculation system. Human mind includes the processes filling experience with value, sense and meaning. From Vygotsky's point of view, meaning acquisition demands not only the language, but also grasping of a cultural context in which the language is used. Intellectual development consists in the development of some higher culturally filled symbolic structures, each of them being able to combine with or even replace the earlier existing one, just like algebra absorbs and replaces arithmetics.

It should be noted that J. Bruner, one of the founders of cognitive science and cognitive psychology, is a consecutive supporter of L.S. Vygotsky's school and its interpretation of culture. At the 2nd Congress on socio-cultural research J.Bruner addressed the conferences «Vygotsky - Piaget» with the report «Celebration of a Variety: Piaget and Vygotsky» [19]. J. Bruner began his speech with the remark: «Researchers of human development are extremely lucky, that there exist such two giants - Jean Piaget and Lion Vygotsky, - who inspire our aspiration» [20].

It should also be noted that new technological structure (the sixth technological order), which characterizes the current state of social production urgently requires a new person who is able to responsibly manage the powerful potential of knowledge acquired by modern science. In this regard, higher education is faced with the task of transferring humanitarian disciplines teaching to a new qualitative (anthropological) level which will allow preserving and reproducing not only the intellect, but also the reflecting person himself. Such task can be fulfilled through a cooperation of natural sciences and humanitarian departments, through interdisciplinary contacts based on certain methodological and theoretical approaches, through cognitive-oriented projects of scientists and teachers specializing in the fields of humanitarian, technical, mathematical and natural knowledge. 


\section{References}

1. V.V. Mironov, E.A. Kosilova, T.A. Varhotov, P.N. Kostylev, A.P. Besedin, Vestnik MSU. Series 7. Philosophy. 2, 59-71. 65 (2017)

2. E.Ja. Rezhabek, A.A. Filatova. Cognitive Culturology (Aletejja, St. Petersburg, 2010)

3. A.A. Filatova, Concept as a constitutive element of culture: a cognitive approach (Rostov-on-Don, 2007)

4. G. Lakoff, Women, Fire and Dangerous Things. What Categories Reveal about the Mind (University of Chicago Press, Chicago and London, 1987)

5. J. Bruner, Acts of Meaning (Harvard University Press, Cambridge, 1990)

6. I.V. Chernikova, D.V. Chernikova, Vestnik TSU. Philosophy. Sociology. Politology. 4 (36), 107 (2016)

7. T.V. Chernigovskaja, Cheshire smile of Schrödinger cat: language and consciousness. (Jazyki slavjanskoj kul'tury, Moscow, 2013)

8. M.A. Bogdanova, Vserossijskaja konferencija po kognitivnoj nauke KISE-2017. 292297. (2017)

9. P.A. Florenskij, Russkij kosmizm: Antologija filosofskoj mysli (Pedagogika-Press, Moscow, 1993)

10. L.S. Abrosimova, Word formation in the linguistic categorization of the world. (SFU, Rostov-on-Don, 2015)

11. V. Vs. Ivanov, Human Science: An Introduction to Modern Anthropology: Lecture Course (RGGU, Moscow, 2004)

12. D.C. Dennett, Consciousness Explained (Little, Brown and Company, Boston, 1991)

13. W. Goodenough, Cultural anthropology and linguistics (Georgetown University, Washington, DC, 1957)

14. R.G. D'Andrade, New Direction in Psychological Anthropology (Cambridge University Press, Cambridge, 1994)

15. M. Cowell, Socio-historical approach to the psychology of teaching (Pedagogika, Moscow, 1989)

16. N.S. Julina, Philosophical Naturalism: About Daniel Dennett's book «Freedom Evolves» (Kanon+ROOI "Reabilitatsiya", Moscow, 2007)

17. C. Geertz, The Interpretation of Culture (Basic Books, New York, 1973)

18. L.S. Vygotskij, A.R. Lurija. Studies on the history of behavior. Monkey, primitive, child (Pedagogika-Press, Moscow, 1993)

19. J. Bruner, Psychology issues, 4, 6 (2001)

20. J. Bruner, The Culture of Education (Harvard University Press, Cambridge, Mass., 1996) 